\title{
Prevalence of autism spectrum disorder symptoms in a paediatric neurology clinic at a tertiary hospital in Uganda
}

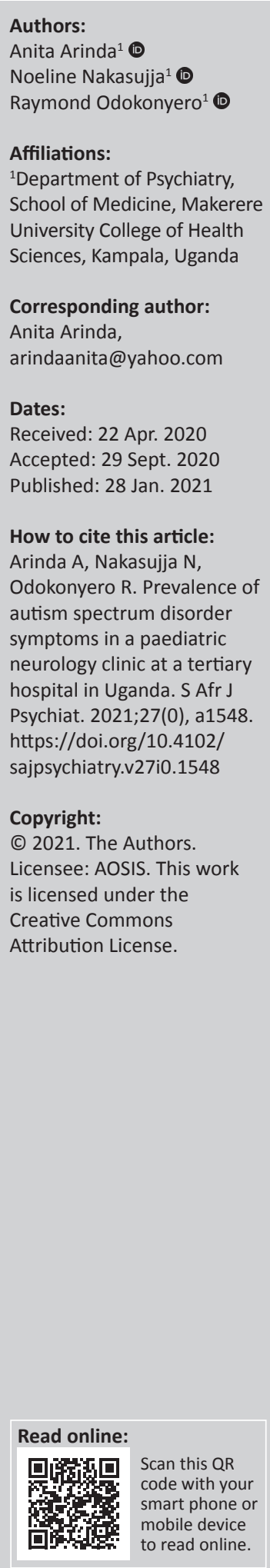

Background: Children with neurological disorders are more likely to present with autism spectrum disorder (ASD) symptoms and get an ASD diagnosis. Despite the large burden of childhood neurological disorders in Uganda, there is limited information on ASD amongst children with neurological disorders in Uganda.

Aim: The aim of this study was to determine the prevalence and factors associated with ASD symptoms amongst children attending the paediatric neurology clinic.

Setting: The study was conducted at the paediatric neurology clinic of Mulago National Referral Hospital in Uganda.

Methods: This was a cross-sectional study of 318 children aged 2-9 years. After obtaining consent, a socio-demographic questionnaire and the Social Communication Questionnaire were administered to the caregivers of the children. Additional questions were administered to assess the prenatal, birth and postnatal characteristics of the children. Sample characteristics were described using frequencies and means. Bivariate analysis was carried out using chisquare test and Fisher's exact test. Multiple logistic regression models were used to assess which factors were independently associated with ASD symptoms.

Results: The mean age of the children was 5 years and $58.2 \%$ were males. The prevalence of significant ASD symptoms was found to be $45 \%$. Factors negatively associated with significant ASD symptoms were female sex (odds ratio [OR] 0.48 [95\% CI 0.24, 0.98]) and ability to speak (OR 0.09 [95\% CI 0.04, 0.2]). The history of delayed developmental milestones was positively associated with significant ASD symptoms (OR 3.3 [95\% CI 1.59, 6.84]).

Conclusion: The prevalence of ASD symptoms is high in children with neurological disorders. Children, especially those with delayed developmental milestones, should routinely be screened for ASD.

Keywords: prevalence; associated factors; autism spectrum disorder; neurological disorders; Uganda.

\section{Introduction}

Autism spectrum disorder (ASD) is a neurodevelopmental disorder characterised by persistent deficits in social communication and social interaction and restricted and repetitive behaviours, interests and activities. ${ }^{1}$

These deficits occur in multiple contexts and are characterised by deficits in socio-emotional reciprocity, verbal and non-verbal communication used for social interaction and difficulty in developing and maintaining relationships. ${ }^{2}$ These features vary depending on age, culture and intellectual ability. Verbal communication deficits range from speech delay, monotonous speech, echolalia and poor comprehension of speech to a complete lack of spoken language. Non-verbal communication deficits include poor eye contact, difficulty in use and understanding of facial expression or gestures. An early feature of social communication deficit in ASD is impaired joint attention that manifests as lack of pointing, showing or bringing objects to share interests with others or failure to follow someone's pointing or eye gaze. ${ }^{3}$ Deficits in socio-emotional reciprocity, which is the ability to engage with others and share feelings, include little or no initiation of conversation or other forms of interaction with others and decreased or absent imitation of others. Deficits in developing, maintaining and understanding relationships may present as absent, reduced or atypical social interest, manifested by rejection of others, passivity or 
inappropriate approaches that seem aggressive or disruptive. These difficulties are particularly evident in young children, in whom there is often a lack of shared social play, imagination and insistence on playing by very fixed rules. Children with ASD also have varying presentation of restricted and repetitive behaviours. Repetitive behaviour may include stereotypical motor behaviour such as hand flapping, repetitive use of objects like lining up toys, or repetitive speech (echolalia), whilst restricted behaviour is characterised by insistence on sameness or highly fixated interests.

According to a mini review by Suresh and colleagues, the global mean prevalence of ASD was estimated at 26.7 per 10000 population. ${ }^{4}$ However, children with neurological disorders are reported to have increased chances of receiving an ASD diagnosis and higher rate of problems associated with ASD compared with those without neurological disorders. ${ }^{5}$ In a study by Ryland and colleagues amongst 11-13-year-old children, it was found that those with neurological disorders had significantly higher scores on a screening tool for ASD symptoms compared with those without neurological disorders. ${ }^{6}$ The findings of this study also showed that $14.1 \%$ of the children with neurological disorders had significant ASD symptoms. In a study amongst children with hydrocephalus, significant ASD symptoms were reported in $13 \%$ of children aged 5-12 years. ${ }^{7}$ The ASD symptoms in these children were significantly associated with having another neurological disorder, for example, cerebral palsy and epilepsy. Amongst children with epilepsy, the prevalence of significant ASD symptoms as determined by various screening tools has been estimated to range between $26 \%$ and $32 \% .{ }^{8,9}$ A study amongst children with cerebral palsy also reported a high prevalence of ASD symptoms of $19 \%$ and these children scored higher on the Autism Spectrum Screening Questionnaire compared with their counterparts without cerebral palsy. ${ }^{10}$

Various factors have been postulated to be associated with ASD amongst children. Perinatal factors have been studied extensively and those found to be associated with ASD, include gestational diabetes, maternal infections and drug use during pregnancy, caesarean delivery, preterm delivery, postterm delivery, low Apgar score and small for gestational age. ${ }^{11}$ Amongst the socio-demographic factors, high socio-economic status and male sex have been associated with ASD. Some specific factors that are significantly associated with ASD symptoms in children with neurological disorders include family history of mental and neurological disorders, ${ }^{12}$ the presence of comorbid psychiatric disorders like attention deficit hyperactivity disorder ${ }^{10}$ and intellectual disability. ${ }^{13}$

Neurological disorders in children represent a significant proportion of global burden of disease because they are a major cause of morbidity, disability, mortality and poor quality of life. ${ }^{14}$ Most of this burden occurs in resourcelimited settings of Asia and Africa. In Uganda, there is a considerable burden of neurological disorders in children with epilepsy and motor disorders, cerebral palsy being the most common. ${ }^{15}$ The prevalence of epilepsy in children in a recent population study in Uganda was found to be 10.3 per 1000 children, ${ }^{16}$ whilst that of cerebral palsy is estimated to be 2.9 per 1000 children. ${ }^{17}$ Despite the presence of literature suggesting comorbidity of ASD and neurological disorders, there is limited information on ASD amongst children with neurological concerns in Uganda. This descriptive crosssectional study was designed to determine the prevalence of ASD symptoms amongst children attending the paediatric neurology clinic in Mulago Hospital and the factors associated with ASD symptoms in these children. In this study, we defined the prevalence of those children attending the neurology clinic over the 3 months of recruitment that had significant ASD symptoms.

\section{Methods \\ Study design and setting}

This was a cross-sectional study conducted in the paediatric neurology clinic of Mulago National Referral Hospital, which is one of the two national referral hospitals in Uganda. It is located in Kampala district, the capital city of Uganda, about 4 kilometres $(\mathrm{km})$ from the city centre. It is the largest hospital in Uganda, with a bed capacity of 1500 . The hospital provides both inpatient and outpatient services for patients from all over the country and training of students of all cadres. The paediatric neurology clinic is a specialised outpatient clinic, which receives children with neurologic disorders from all over the country. It runs twice a week and about 50 children are attended to on clinic days. The conditions managed in this clinic include epilepsy, cerebral palsy and muscular dystrophy. It is also in this clinic that a number of neurodevelopmental disorders including ASD are usually seen before they are sent to the child and adolescent psychiatry clinic for further assessment and management.

\section{Eligibility criteria}

Parents or caregivers of children aged 2-9 years were approached to participate in the study. Those who consented to participation were included in the study. The age of 2 years was considered as the lower limit for this study because at this age parents or caregivers started noticing symptoms that are characteristic of ASD. The age of 9 years was considered as the upper limit so as to limit this study to the age group below adolescence (the World Health Organization defines adolescence as the age group of 10-17 years).

Children who were too sick and needed urgent medical attention and those whose caregivers lived with them for less than 6 months and as such had insufficient information about the behaviour of the child were excluded from the study.

\section{Sample size calculation}

Sample size was calculated based on Leslie Kish's (1965) formula. With an expected proportion of $29.3 \%$ of children having ASD (Mpaka et al., 2016) and a standard error of $\pm 5 \%$, the sample size was estimated at 318 . 


\section{Study procedure}

The study participants were enrolled from the paediatric neurology clinic of Mulago Hospital between November 2018 and January 2019. Every child aged 2-9 years was considered as the potential participant for the study.

On a clinic day, the principal investigator and two research assistants (who were mental health nurses) approached the potential participants and their caregivers to assess for eligibility and interest in the research project. They explained the purpose of the study and procedures and obtained informed consent from the parents/caregivers. The research questionnaires took $45 \mathrm{~min}$ to complete. Those who were found to have significant ASD symptoms were directed to the child and adolescent mental health clinic to receive further assistance.

\section{Study measures and instruments \\ Autism spectrum disorder symptoms}

Autism spectrum disorder symptoms are impairments in social communication, social interaction and restricted, repetitive patterns of behaviour as seen in children with ASD. These were measured using the Social Communication Questionnaire (SCQ). ${ }^{18}$ This 40-item questionnaire was researcher-administered and used to obtain information about the child's behaviour from the caregiver. Of the 40 items, 27 items address deficits in social communication and interaction, whilst eight questions are focused on restricted, repetitive patterns of behaviour, interests or activities. Each item is scored 'yes/no', with a score of 1 or 0 to indicate the presence or absence of a given abnormal behaviour. The items are summed up to give a total score of 0-39 for verbal children and 0-33 for non-verbal children.

The SCQ is based on the Autism Diagnostic InterviewRevised, ${ }^{19}$ a semi-structured interview tool used as a gold standard for the diagnosis of ASD in individuals with a mental age of 18 months and above. The SCQ, initially validated amongst individuals of ages $4-40$ years, was found to have a sensitivity of $85 \%$ and specificity of $75 \% .{ }^{18}$ Subsequent validation studies that were conducted in only children above 4 years found sensitivity scores ranging from $88 \%$ to $97.4 \%$ and specificity values from $62 \%$ to $96.5 \%{ }^{20,21,22}$ This screening tool has also been used and validated in African settings. A validation study in Mali amongst individuals 4-20 years of age reported a sensitivity of $71 \%$ and a specificity of $72 \%,{ }^{23}$ whilst a South African study amongst children of 2.5-14 years found a sensitivity of $77 \%$ and specificity of $100 \%$ if a cut-off of 15 was used..$^{24}$ Many studies have been conducted to validate the SCQ in younger children. These studies conducted in children below 4 years have found sensitivities ranging from $79.6 \%$ to $93 \%$ and specificities from $40 \%$ to $89 \% . .^{25,26,27,28} \mathrm{~A}$ cut-off of 15 has been shown to have a fairly good specificity and sensitivity in distinguishing between children with ASD and those with other developmental disabilities. ${ }^{29}$ In this study, significant ASD symptoms were defined as a score of greater than 15 on the SCQ.

\section{Socio-demographic characteristics}

Socio-demographic characteristics of both the child and the parents were assessed using a socio-demographic questionnaire. Child demographic characteristics included age, sex, education level, primary caregiver and family history of mental illness.

\section{Perinatal characteristics}

The following additional questions were asked to assess the prenatal, birth and postnatal characteristics: maternal and paternal age at the conception of the child, history of gestational diabetes and hypertension, mode of delivery, preterm delivery, birth weight, breastfeeding history and history of illness in the neonatal period.

\section{Patient's medical records}

The participant's clinical records obtained included the neurological condition, history of delayed milestones and the presence or lack of speech.

\section{Data analysis}

Data analysis was carried out with STATA version 14. Frequencies and percentages were computed for the categorical variables, whilst means and standard deviation were used to describe the continuous variables. Chi-square tests and Fisher's exact test were used for bivariate analysis. Variables whose level of significance was 0.2 or less at bivariate analysis were included in the multiple logistic regression model for multivariate analysis.

A $p$-value of less than or equal to 0.05 was considered to be statistically significant.

\section{Ethical consideration}

This study was approved by Makerere University School of Medicine Research and Ethics Committee (\#REC REF 2018110). The caregivers of all the children gave written informed consent and children of 8-9 years gave written assent to participate in the study.

\section{Results}

\section{Socio-demographic characteristics}

The sample included 318 children with neurological disorders. Of the participants, 185 (58.2\%) were males, with a female to male ratio of 1:1.4. The participants' age ranged from 2 to 9 years, with a mean age of 5.0 years. The rest of the participant characteristics are represented in Table 1.

\section{Clinical characteristics}

The children in this clinic presented with a number of neurological conditions, with the most common being epilepsy (57.2\%) and cerebral palsy (34.6\%). The rest of the disorders are represented in Table 1 . More than half of the participants (182; 57.2\%) had a history of delayed developmental milestones (sitting, standing, walking and talking). 
TABLE 1: Socio-demographic and clinical characteristics of participants.

\begin{tabular}{|c|c|c|}
\hline Variable & Frequency $(N=318)$ & Percentage \\
\hline \multicolumn{3}{|l|}{ Sex of the child } \\
\hline Male & 185 & 58.2 \\
\hline Female & 133 & 41.8 \\
\hline \multicolumn{3}{|c|}{ Primary caregiver } \\
\hline Both parents & 229 & 72.0 \\
\hline Mother & 61 & 19.2 \\
\hline Father & 13 & 4.1 \\
\hline Othert & 15 & 4.7 \\
\hline \multicolumn{3}{|c|}{ School attendance } \\
\hline Yes & 125 & 39.3 \\
\hline No & 193 & 60.7 \\
\hline \multicolumn{3}{|c|}{ Family history of mental illness } \\
\hline Yes & 43 & 13.5 \\
\hline No & 275 & 86.5 \\
\hline \multicolumn{3}{|c|}{ Neurologic condition } \\
\hline Epilepsy & 182 & 57.2 \\
\hline Cerebral palsy & 110 & 34.6 \\
\hline Others $\$$ & 26 & 8.2 \\
\hline \multicolumn{3}{|l|}{ Ability to speak } \\
\hline Yes & 188 & 59.1 \\
\hline No & 130 & 40.9 \\
\hline \multicolumn{3}{|c|}{ Delayed developmental milestones } \\
\hline Yes & 182 & 57.2 \\
\hline No & 136 & 42.8 \\
\hline
\end{tabular}

$\dagger$, Aunt, grandmother, foster parents.

‡, Erb’s palsy, Global Developmental Disorder, Myasthenia Gravis, Sickle cell disease, Stroke.

TABLE 2: Prenatal, birth and postnatal characteristics of the participants.

\begin{tabular}{|c|c|c|}
\hline Variable & Frequency $(N=318)$ & Percentage \\
\hline \multicolumn{3}{|l|}{ Parental characteristics } \\
\hline \multicolumn{3}{|c|}{ Maternal age at conception } \\
\hline$<40$ years & 314 & 98.7 \\
\hline$\geq 40$ years & 4 & 1.3 \\
\hline \multicolumn{3}{|c|}{ Paternal age at conception } \\
\hline$<40$ years & 278 & 88.3 \\
\hline$\geq 40$ years & 37 & 11.7 \\
\hline \multicolumn{3}{|c|}{ History of gestational hypertension } \\
\hline Yes & 29 & 9.1 \\
\hline No & 289 & 90.9 \\
\hline \multicolumn{3}{|c|}{ History of gestational diabetes } \\
\hline Yes & 2 & 0.6 \\
\hline No & 316 & 99.4 \\
\hline \multicolumn{3}{|l|}{ Preterm birth } \\
\hline Yes & 38 & 11.9 \\
\hline No & 280 & 88.1 \\
\hline \multicolumn{3}{|l|}{ Mode of delivery } \\
\hline Normal delivery & 245 & 77.0 \\
\hline Instrumental delivery & 12 & 3.8 \\
\hline Caesarean delivery & 61 & 19.2 \\
\hline \multicolumn{3}{|l|}{ Child characteristics } \\
\hline \multicolumn{3}{|l|}{ Birth weight } \\
\hline$<2.5 \mathrm{~kg}$ & 31 & 10.2 \\
\hline $2.5 \mathrm{~kg}-4.0 \mathrm{~kg}$ & 264 & 87.1 \\
\hline$>4.0 \mathrm{~kg}$ & 23 & 7.2 \\
\hline \multicolumn{3}{|c|}{ Illness in neonatal period } \\
\hline Yes & 144 & 45.3 \\
\hline No & 174 & 54.7 \\
\hline \multicolumn{3}{|c|}{ Duration of breastfeeding } \\
\hline Never & 7 & 2.2 \\
\hline$<6$ months of age & 20 & 6.3 \\
\hline$\geq 6$ months of age & 291 & 91.5 \\
\hline
\end{tabular}

\section{Prenatal, birth and postnatal characteristics of the study participants}

The majority of respondents reported no history of gestational diabetes $(99.4 \%)$ or gestational hypertension $(90.9 \%)$. The most common mode of delivery was normal delivery (77\%), followed by caesarean delivery $(19.2 \%)$. The rest of the perinatal factors are presented in Table 2.

\section{Prevalence and factors associated with significant autism spectrum disorder symptoms}

This study found that 143 participants (45\%) had significant ASD symptoms, that is, screened positive on the SCQ (above the cut-off of 15).

Table 3 illustrates the bivariate analyses of socio-demographic characteristics and clinical characteristics. The factors that were significantly associated with significant ASD symptoms on bivariate analysis included not attending school, lack of speech and delayed developmental milestones.

Table 4 illustrates the bivariate analyses of the perinatal characteristics. The history of illness in the neonatal period was significantly associated with significant ASD symptoms.

The results of the multivariate logistic regression analysis indicated that females were $52 \%$ less likely to screen positive

TABLE 3: Bivariate analysis of socio-demographic and clinic characteristics of the study participants.

\begin{tabular}{|c|c|c|c|c|c|}
\hline \multirow[t]{2}{*}{ Variable } & \multicolumn{2}{|c|}{$\begin{array}{c}\text { SCQ score } \leq 15 \dagger \\
N=175\end{array}$} & \multicolumn{2}{|c|}{$\begin{array}{c}\text { SCQ score }>15 \\
N=143\end{array}$} & \multirow[t]{2}{*}{$p$} \\
\hline & $n$ & $\%$ & $n$ & $\%$ & \\
\hline \multicolumn{6}{|l|}{ Sex of child } \\
\hline Male & 96 & 54.9 & 89 & 62.2 & \multirow{2}{*}{0.185} \\
\hline Female & 79 & 45.1 & 54 & 37.8 & \\
\hline \multicolumn{6}{|c|}{ Primary caregiver } \\
\hline Both parents & 133 & 76.0 & 96 & 67.1 & \multirow{4}{*}{0.212} \\
\hline Mother & 8 & 4.5 & 5 & 3.5 & \\
\hline Father & 28 & 16.0 & 33 & 23.1 & \\
\hline Other§ & 6 & 3.5 & 9 & 6.3 & \\
\hline \multicolumn{6}{|c|}{ School attendance } \\
\hline Yes & 110 & 63.5 & 15 & 10.5 & \multirow{2}{*}{$<0.001$} \\
\hline No & 65 & 36.5 & 128 & 89.5 & \\
\hline \multicolumn{6}{|c|}{ Family history of mental illness } \\
\hline Yes & 25 & 14.3 & 18 & 12.6 & \multirow{2}{*}{0.660} \\
\hline No & 150 & 85.7 & 125 & 87.4 & \\
\hline \multicolumn{6}{|c|}{ Neurological condition } \\
\hline Cerebral palsy & 16 & 9.1 & 94 & 65.7 & \multirow{3}{*}{$<0.001$} \\
\hline Epilepsy & 144 & 82.3 & 38 & 26.6 & \\
\hline Other & 15 & 8.6 & 11 & 7.7 & \\
\hline \multicolumn{6}{|c|}{ Ability to speak } \\
\hline Yes & 157 & 89.7 & 31 & 78.3 & \multirow{2}{*}{$<0.001$} \\
\hline No & 18 & 10.3 & 112 & 78.3 & \\
\hline \multicolumn{6}{|c|}{ History of delayed milestones } \\
\hline Yes & 65 & 37.1 & 117 & 81.8 & \multirow{2}{*}{$<0.001$} \\
\hline No & 110 & 62.9 & 26 & 18.2 & \\
\hline \multicolumn{6}{|c|}{ SCQ, Social Communication Questionnaire. } \\
\hline \multicolumn{6}{|c|}{$\dagger$, Non-significant ASD symptoms. } \\
\hline \multicolumn{6}{|c|}{ \#, Significant ASD symptoms. } \\
\hline$\S$, Aunt, grandm & paren & & & & \\
\hline
\end{tabular}


TABLE 4: Logistic regression estimates of factors associated with screening positive for autism spectrum disorder.

\begin{tabular}{|c|c|c|c|c|c|c|}
\hline \multirow[t]{2}{*}{ Variable } & \multicolumn{2}{|c|}{ Unadjusted OR } & \multirow[t]{2}{*}{$p$} & \multicolumn{2}{|c|}{ Adjusted OR } & \multirow[t]{2}{*}{$p$} \\
\hline & OR & $95 \% \mathrm{Cl}$ & & OR & $95 \% \mathrm{Cl}$ & \\
\hline \multicolumn{7}{|l|}{ Sex } \\
\hline Male & 1 & - & - & 1 & - & - \\
\hline Female & 0.74 & $0.47,1.16$ & 0.185 & 0.48 & $0.24,0.98$ & 0.044 \\
\hline \multicolumn{7}{|l|}{ School attendance } \\
\hline Yes & 1 & - & - & 1 & - & - \\
\hline No & 0.07 & $0.04,0.13$ & $<0.001$ & 0.45 & $0.19,1.07$ & 0.07 \\
\hline \multicolumn{7}{|c|}{ Neurological condition } \\
\hline Others $\dagger$ & 1 & - & - & 1 & - & - \\
\hline Cerebral Palsy & 8.01 & $3.13,20.54$ & $<0.001$ & 2.39 & $0.72,7.94$ & 0.155 \\
\hline Epilepsy & 0.36 & $0.15,0.85$ & 0.019 & 0.64 & $0.21,1.96$ & 0.434 \\
\hline \multicolumn{7}{|l|}{ Ability to speak } \\
\hline No & 1 & - & - & 1 & - & - \\
\hline Yes & 0.03 & $0.02,0.06$ & $<0.001$ & 0.09 & $0.04,0.2$ & $<0.001$ \\
\hline \multicolumn{7}{|c|}{ History of delayed developmental milestones } \\
\hline No & 1 & - & - & 1 & - & - \\
\hline Yes & 7.62 & $4.51,12.86$ & $<0.001$ & 3.3 & $1.59,6.84$ & 0.001 \\
\hline \multicolumn{7}{|l|}{ Neonatal illness } \\
\hline No & 1 & - & - & 1 & - & - \\
\hline Yes & 3.40 & $2.14,5.40$ & $<0.001$ & 1.46 & $0.72,2.96$ & 0.300 \\
\hline \multicolumn{7}{|c|}{ Duration of breastfeeding } \\
\hline Never & 1 & - & - & 1 & - & - \\
\hline$<6$ months of age & 0.6 & $0.09,3.89$ & 0.592 & 0.56 & $0.03,11.23$ & 0.708 \\
\hline$\geq 6$ months of age & 0.31 & $0.06,1.6$ & 0.160 & 1.07 & $0.07,15.81$ & 0.959 \\
\hline
\end{tabular}

OR, odds ratio.

$\dagger$, Erb's palsy, Global Developmental Disorder, Myasthenia Gravis, Sickle cell disease, stroke.

for ASD (odds ratio [OR] 0.48 [95\% CI 0.24, 0.98]). The children who had the ability to speak were $91 \%$ less likely to screen positive for ASD compared with those who were unable to speak (OR 0.09 [95\% CI 0.04, 0.2]). Those with delayed milestones were 3.3 times more likely to screen positive for ASD than those without a history of delayed milestones (OR 3.3 [95\% CI 1.59, 6.84]).

\section{Discussion}

This study was designed to determine the prevalence and factors associated with ASD symptoms amongst children attending the paediatric neurology clinic of Mulago Hospital. The prevalence of significant ASD symptoms was estimated to be $45.0 \%$ in this population. Female sex and ability to speak were negatively associated with significant ASD symptoms, whilst history of delayed milestones was positively associated with significant ASD symptoms.

The estimate of prevalence is consistent with findings from a number of other studies that have shown ASD symptoms to be higher in children with neurological disorders compared with healthy peers or children with other chronic disorders. ${ }^{6,8}$ This high prevalence can be attributed to the nature of the setting from which the study population was obtained. This paediatric neurology clinic, which is situated at the national referral hospital, is a specialised clinic that provides medical care to children with some of the most severe neurological concerns that are referred from other health facilities. A number of factors may account for the increased prevalence of ASD symptoms in children with neurological disorders.
An overlap between aetiological mechanisms and symptoms of the neurological disorders and ASD may contribute to the co-occurrence of neurological disorders and ASD symptoms. ${ }^{30,31}$ A number of children with neurological disorders also present with difficulties in cognitive functioning, especially intellectual disability, which may lead to decreased social functioning and deficient social relationships and may present with symptoms characteristic of ASD. ${ }^{32}$ In addition, the disabilities that commonly occur in neurological disorders also increase chances of children being rejected by others, thus affecting social relationships with their peers. ${ }^{33}$

The prevalence in this study, however, is higher than that shown in other studies that looked at ASD symptoms in neurological disorders. A study by Ryland and colleagues, which assessed for ASD symptoms amongst children with neurological disorders, reported a prevalence of $14.1 \% .^{6}$ Their prevalence could have been lower because they considered an older age group of 11-13 years. In addition, they considered only schoolgoing children that possibly ruled out more impaired children who usually fail to go to school. It is also worth noting that a different tool was used for assessment and hence produced different results. Other studies focusing on ASD symptoms, in particular neurological disorders including epilepsy and cerebral palsy, have also reported a lower prevalence compared with our study. Clarke and colleagues found a prevalence of $32 \%$ in children with epilepsy attending tertiary care, ${ }^{34}$ whilst Bjorgaas and colleagues found a prevalence of $20 \%$ in children with cerebral palsy. ${ }^{10}$ These studies, however, only considered schoolgoing children of ages different from those in our study (2-18 years and 11-13 years, respectively) and also ruled out intellectual disability. Some studies have shown that children with epilepsy and intellectual disability are at substantially increased risk of autism relative to those with epilepsy who are of normal intellectual abilities. ${ }^{35}$ It is, however, also important to note that this study was carried out in a lower resource setting compared with the given studies. In these settings, services for disability are scarce and thus it is the children with more severe disability that are brought to health facilities, whilst the milder cases do not enter the healthcare system. Therefore, this may explain why a large number of children in this clinic presented with ASD symptoms that may have complicated the already existing neurological condition and thus prompting caretakers to seek medical care.

\section{Factors associated with autism spectrum disorder symptoms}

According to this study, being male was positively associated with screening positive for ASD symptoms. This is in line with study findings that indicate the rate of ASD to be significantly higher in males than in females, with a frequently stated male to female ratio of $4: 1.36,37,38$ The explanation for this difference is not clear but there are various theories to try and explain this. One of the explanations is the 'empathising-systemising' theory, which postulates that typically females exhibit more empathising 
(able to identify oneself with other's mental state and to respond to these feelings and thoughts with an appropriate response) and less systemising (ability to analyse and build systems) compared with typical males. ${ }^{39}$ Females with ASD may also display superficial social skills, which may mask ASD symptomatology impacting the identification of the disorder. ${ }^{40}$ This has been termed as the 'camouflage' hypothesis. Compared with their male counterparts with ASD, it is increasingly recognised that females with ASD have a stronger ability to imitate socially acceptable behaviour, particularly the females with higher cognitive abilities. ${ }^{40}$ This capacity to camouflage social difficulties in social situations is considered to be one of the main features of the female phenotype of ASD.

Social imitation or camouflaging enables some level of social success and coping, which results in some females never receiving the diagnosis of ASD because they may not exhibit any observable functional impairment. ${ }^{41}$ An alternative biological explanation suggested is the notion of 'femalespecific protective factors' (FPF), which suggests that females can withstand a larger etiological load than males before reaching diagnostic thresholds of ASD.42

There was also a significant association between inability to speak and significant ASD symptoms. The lack of expressive speech has been described as a common finding in African children with ASD. ${ }^{43,44}$ Lagunju and colleagues reported that more than $50 \%$ of children with ASDs in a neurology clinic in Nigeria were non-verbal. ${ }^{45}$ Bakare et al. suggested that selection of severe cases in presentation to medical care may be a potential contributor especially in the African context. ${ }^{43}$ Some validation studies have reported increased sensitivity of the SCQ amongst non-verbal children. ${ }^{46}$ Non-verbal children have also been shown to score higher on the SCQ despite the fact that they have no data for six items that are strictly applicable to verbal children. ${ }^{47,48}$ One explanation given for this finding is that non-verbal children may show more severe features of ASD compared with their verbal counterparts. ${ }^{48}$

This study also showed a significant association between delay in milestones and ASD symptoms. This has been noted before in another study that reported delays in motor milestones in children with ASD compared with normal children. ${ }^{49,50}$ The motor delays in early childhood may contribute to later developmental delays in verbal and gestural communication, a characteristic of ASD. ${ }^{51}$ They may also negatively affect balance, social appearance and motivation to engage in social activities involving gross motor behaviours, for example, playing ball games. ${ }^{52}$ Furthermore, motor delays can influence frequency of challenging behaviour, especially avoidant behaviour, such as tantrums, commonly reported in children with ASD.

Education attainment was not found to be correlated with screening positive for ASD in this study. Amongst the children who screened positive for ASD, the number of those who were not attending school was significantly higher than those who were attending the school. However, on multivariate analysis, this association became insignificant. This is not in line with studies that have reported that ASD negatively affects education attainment amongst affected individuals. ${ }^{53}$ The findings in this study may be explained by the fact that even the children that screened negative for ASD symptoms have other factors that may also affect school attendance in these children, for example, socio-economic status and age.

There was no association between perinatal factors and ASD in this study. There have been mixed findings about this association in various studies, ${ }^{11}$ with some studies reporting a positive association ${ }^{54,55}$ whilst others reporting no association. ${ }^{56,57}$ The only factor that has consistently shown an association is advanced paternal age. In our study, there were a small number of fathers above 40 years of age and this could have affected these results.

\section{Strengths and limitations}

The main strength of this study was that it had a large sample size that increased the power of this study and the generalisability of the results. This study adds to the limited database of ASD within the African context.

This study had several limitations. Firstly, this is a crosssectional study; thus, the temporal relationship between ASD and neurological disorders could not be established. Therefore, inferences about causation could not be made in this cross-sectional study because the exposure and outcome were measured at the same time. Secondly, there was no independent validation of ASD symptoms by direct assessment of the children by a qualified clinician. The SCQ cannot be used to make a diagnosis of ASD as this requires a more detailed description of actual behaviour, onset and development over time as well as effect on functioning. ${ }^{18}$ Parent or caregiver reports on a screening questionnaire with 'yes' or 'no' answers, therefore, cannot replace a clinical validation of diagnosis. Speech was also not assessed by a qualified specialist, but we mainly depended on parental reports and these findings may have not taken into account developmental age. Thirdly, there was potential for recall bias caused by requirement for respondents to provide information regarding experiences or events from the past. There are also limitations in the generalisability of these findings to other children with neurological conditions in other settings as this study was performed in a national referral hospital that usually receives the more severe cases.

\section{Implications and recommendations}

The present findings highlight the need for awareness amongst clinicians about the likelihood that a number of children with neurological disorders in Uganda might be experiencing significant ASD-related challenges. It is, therefore, important that clinicians have access to and use 
screening instruments to enable them to identify these problems that may pose a great challenge to the affected children and their families. Emphasis can be placed on children who present with delays in developmental milestones.

Further research is recommended amongst those who screen positive using diagnostic tools such as the Autism Diagnostic Interview-Revised and the Autism Diagnostic Observation Schedule.

\section{Conclusion}

This study found that almost half of the children attending a neurology clinic in a tertiary hospital in Uganda presented with significant ASD symptoms. The children with significant ASD symptoms were most likely males, had limited or no speech and history of developmental delays.

\section{Acknowledgements}

The authors would like to thank Dr Nelson Mukiiza who helped with the statistical analysis and also gave wonderful suggestions that improved this article.

\section{Competing interests}

The authors declare they have no financial or personal relationships that may have inappropriately influenced them in writing this article.

\section{Authors' contributions}

A.A. conceptualised and designed the study, collected the data and wrote the article. N.N. and R.O. supervised the study and helped in the writing of the article. All authors have read and approved the final manuscript.

\section{Funding information}

The study was made possible by a scholarship fund awarded to Anita Arinda by the Neuro-Genetics of African Populations (Neuro-GAP) study.

\section{Data availability statement}

All data that were generated and analysed during this study are included in this published article.

\section{Disclaimer}

The views and opinions expressed in this article are the authors' own and do not necessarily represent the official policy or position of any institution or funder of the authors.

\section{References}

1. American Psychiatric Association. Diagnostic and statistical manual of mental disorders (DSM-5 $\left.{ }^{\oplus}\right)$. Washington, DC: American Psychiatric Pub; 2013

2. Lai M-C, Lombardo MV, Baron-Cohen S. Autism. Lancet. 2014;383(9920):896-910. https://doi.org/10.1016/S0140-6736(13)61539-1
3. Jones EA, Carr EG. Joint attention in children with autism: Theory and intervention. Focus Autism Other Dev Disabil. 2004;19(1):13-26. https://doi.org/10.1177/1088 3576040190010301

4. Poovathinal SA, Anitha A, Thomas RJ, et al., editors. Global prevalence of autism A mini-review [homepage on the Internet]. 2018. Available from: https://www. semanticscholar.org/paper/Global-Prevalence-of-Autism\%3A-A-Mini-ReviewPoovathinal-Anitha/590e87eccf1300a7a821f11779316b2d962322dc

5. Christopher G. Double syndromes: Autism associated with genetic, medical and metabolic disorders. In: Ruth D, Nass YF, editors. Cognitive and behavioral abnormalities of pediatric diseases. New York, NY: Oxford University Press, 2010 p. 11-29.

6. Ryland HK, Hysing M, Posserud M-B, Gillberg C, Lundervold AJ. Autism spectrum symptoms in children with neurological disorders. Child Adolesc Psychiatry Ment symptoms in children with neurological disorders. Child Ado
Health. 2012;6:34. https://doi.org/10.1186/1753-2000-6-34

7. Lindquist B, Carlsson G, Persson EK, Uvebrant P. Behavioural problems and autism in children with hydrocephalus: A population-based study. Eur Child Adolesc Psychiatry. 2006;15(4):214-219. https://doi.org/10.1007/s00787-006-0525-8

8. Clarke DF, Roberts W, Daraksan $M$, et al. The prevalence of autistic spectrum disorder in children surveyed in a tertiary care epilepsy clinic. Epilepsia. 2005;46(12):1970-1977. https://doi.org/10.1111/j.1528-1167.2005.00343.x

9. Reilly $C$, Atkinson $P$, Das KB, et al. Neurobehavioral comorbidities in children with active epilepsy: A population-based study. Pediatrics. 2014;133(6):e1586-e1593. https://doi.org/10.1542/peds.2013-3787

10. Bjorgaas HM, Elgen I, Ryland HK, Hysing M. Autism spectrum symptoms in Spectr Disord. 2014:8(5):581-588. https://doi.org/10.1016/j.rasd.2014.01.011

11. Guinchat V, Thorsen P, Laurent C, Cans C, Bodeau N, Cohen D. Pre-, peri- and neonatal risk factors for autism. Acta Obstet Gynecol Scand. 2012;91(3):287-300. https://doi.org/10.1111/j.1600-0412.2011.01325.x

12. Xie $\mathrm{S}$, Karlsson $\mathrm{H}$, Dalman $\mathrm{C}$, et al. Family history of mental and neurological disorders and risk of autism. JAMA Netw Open. 2019;2(3):e190154. https://doi. org/10.1001/jamanetworkopen.2019.0154

13. Parkes J, White-Koning M, Dickinson HO, et al. Psychological problems in children with cerebral palsy: A cross-sectional European study. J Child Psychol Psychiatr. 2008;49(4):405-413. https://doi.org/10.1111/j.1469-7610.2007.01845.x

14. Newton C. Global burden of pediatric neurological disorders. Semin Pediatr Neurol. 2018;27:10-15. https://doi.org/10.1016/j.spen.2018.03.002

15. Idro R, Newton C, Kiguli S, Kakooza-Mwesige A. Child neurology practice and neurological disorders in East Africa. J Child Neurol. 2010;25(4):518-524. https:// doi.org/10.1177/0883073809357792

16. Kakooza-Mwesige A, Ndyomugyenyi D, Pariyo G, et al. Adverse perinatal events, treatment gap, and positive family history linked to the high burden of active convulsive epilepsy in Uganda: A population-based study. Epilepsia Open. 2017;2(2):188-198. https://doi.org/10.1002/epi4.12048

17. Kakooza-Mwesige A, Andrews C, Peterson S, Wabwire Mangen F, Eliasson AC, Forssberg $\mathrm{H}$. Prevalence of cerebral palsy in Uganda: A population-based study. Lancet Global Health. 2017;5(12):e1275-e1282. https://doi.org/10.1016/S2214 109X(17)30374-1

18. Berument SK, Rutter M, Lord C, Pickles A, Bailey A. Autism screening questionnaire: Diagnostic validity. Br J Psychiatry. 1999;175:444-451. https://doi.org/10.1192/ Diagnostic validit
bjp.175.5.444

19. Lord C, Rutter M, Le Couteur A. Autism diagnostic interview-revised: A revised version of a diagnostic interview for caregivers of individuals with possible pervasive developmental disorders. J Autism Dev Disord. 1994;24(5):659-685. https://doi.org/10.1007/BF02172145

20. Chandler S, Charman T, Baird G, et al. Validation of the social communication questionnaire in a population cohort of children with autism spectrum disorders. J Am Acad Child Adolesc Psychiatry. 2007;46(10):1324-1332. https://doi. org/10.1097/chi.0b013e31812f7d8d

21. Schanding GT Jr., Nowell KP, Goin-Kochel RP. Utility of the social communication questionnaire-current and social responsiveness scale as teacher-report screening tools for autism spectrum disorders. J Autism Dev Disord. 2012;42(8):1705-1716. https://doi.org/10.1007/s10803-011-1412-9

22. Witwer AN, Lecavalier L. Autism screening tools: An evaluation of the social communication questionnaire and the developmental behaviour checklist-autism screening algorithm. J Intellect Dev Disabil. 2007;32(3):179-187. https://doi. org/10.1080/13668250701604776

23. Sangare $M$, Toure $H B$, Toure $A$, et al. Validation of two parent-reported autism spectrum disorders screening tools M-CHAT-R and SCQ in Bamako, Mali.
eNeurological Sci. 2019;15:100188. https://doi.org/10.1016/j.ensci.2019.100188

24. Bozalek F. Autism screening in children: Using the social communication questionnaire in a Western Cape population. Cape Town: University of Cape Town 2013.

25. Allen C, Silove N, Williams K, Hutchins P. Validity of the social communication questionnaire in assessing risk of autism in preschool children with developmental
problems. J Autism Dev Disord. 2007;37(7):1272-1278. https://doi.org/10.1007/ problems. J Autism
s10803-006-0279-7

26. Lee L-C, David AB, Rusyniak J, Landa R, Newschaffer CJ. Performance of the social communication questionnaire in children receiving preschool special education services. Res Autism Spectr Disord. 2007;1(2):126-138. https://doi.org/10.1016/j. rasd.2006.08.004

27. Snow AV, Lecavalier L. Sensitivity and specificity of the modified checklist for autism in toddlers and the social communication questionnaire in preschoolers suspected of having pervasive developmental disorders. Autism. 2008;12(6): 627-644. https://doi.org/10.1177/1362361308097116

28. Wiggins LD, Bakeman R, Adamson LB, Robins DL. The utility of the social communication questionnaire in screening for autism in children referred for early intervention. Focus Autism Other Dev Disabil. 2007;22(1):33-38. https:// doi.org/10.1177/10883576070220010401 
29. Oosterling I, Rommelse $N$, De Jonge $M$, et al. How useful is the Social Communication Questionnaire in toddlers at risk of autism spectrum disorder? J Child Psychol Psychiatry. 2010;51(11):1260-1268. https://doi.org/10.1111/ j.1469-7610.2010.02246.x

30. Weaving LS, Christodoulou J, Williamson SL, et al. Mutations of CDKL5 cause a severe neurodevelopmental disorder with infantile spasms and mental retardation. Am J Hum Genet. 2004;75(6):1079-1093. https://doi.org/10.1086/ 426462

31. Meng $\mathrm{H}$, Xu HQ, Yu L, et al. The SCN1A mutation database: Updating information and analysis of the relationships among genotype, functional alteration, and phenotype. Hum Mutat. 2015;36(6):573-580. https://doi.org/10.1002/humu. 22782

32. Bottcher L, Flachs EM, Uldall P. Attentional and executive impairments in children with spastic cerebral palsy. Dev Med Child Neurol. 2010;52(2):e42-e47. https:// doi.org/10.1111/j.1469-8749.2009.03533.x

33. Nadeau L, Tessier R. Social adjustment of children with cerebral palsy in mainstream classes: Peer perception. Dev Med Child Neurol. 2006;48(5):331336. https://doi.org/10.1017/S0012162206000739

34. Clay S, Schell B, Corrigan P, Ralph RO. On our own, together: Peer programs for people with mental illness. Nashville, TN: Vanderbilt University Press City, 2005 p. 1-299. https://doi.org/10.2307/j.ctv17vf73b

35. Berg AT, Plioplys S, Tuchman R. Risk and correlates of autism spectrum disorder in children with epilepsy: A community-based study. J Child Neurol. 2011;26(5): 540-547. https://doi.org/10.1177/0883073810384869

36. Fombonne E. Epidemiology of pervasive developmental disorders. Pediatr Res. 2009;65(6):591-598. https://doi.org/10.1203/PDR.0b013e31819e7203

37. Halladay AK, Bishop S, Constantino JN, et al. Sex and gender differences in autism spectrum disorder: Summarizing evidence gaps and identifying emerging areas of priority. Mol Autism. 2015;6(1):36. https://doi.org/10.1186/s13229-015-0019-y

38. Werling DM, Geschwind DH. Sex differences in autism spectrum disorders Curr Opin Neurol. 2013;26(2):146-153. https://doi.org/10.1097/WCO.0b013e 32835ee548

39. Baron-Cohen S. Autism: The empathizing-systemizing (E-S) theory. Ann NY Acad Sci. 2009;1156:68-80. https://doi.org/10.1111/j.1749-6632.2009.04467.x

40. Ehlers S, Gillberg C. The epidemiology of asperger syndrome. J Child Psycho Psychiatry. 1993;34(8):1327-1350. https://doi.org/10.1111/j.1469-7610.1993. tb02094.x

41. Allely CS. Understanding and recognising the female phenotype of autism spectrum disorder and the 'camouflage' hypothesis: A systematic PRISMA review. Adv Autism. 2019;5(1):14-37. https://doi.org/10.1108/AIA-09-2018-0036

42. Werling $D M$, Geschwind $D H$. Understanding sex bias in autism spectrum disorder. Proc Natl Acad Sci USA. 2013;110(13):4868-4869. https://doi.org/10.1073/ pnas. 1301602110

43. Bakare MO, Munir KM. Autism spectrum disorders (ASD) in Africa: A perspective. Afr J Psychiatry. 2011;14(3):208-210. https://doi.org/10.4314/ajpsy.v14i3.3
44. Belhadj A, Mrad R, B Halayem M. A clinic and a paraclinic study of Tunisian population of children with autism. About 63 cases. Tunis Med. 2007;84(12):763-767.

45. Lagunju IA, Bella-Awusah TT, Omigbodun OO. Autistic disorder in Nigeria: Profile and challenges to management. Epilepsy Behav. 2014;39:126-129. https://doi. org/10.1016/j.yebeh.2014.08.020

46. Surén $P$, Saasen-Havdahl A, Bresnahan $M$, et al. Sensitivity and specificity of early screening for autism. BJPsych Open. 2019;5(3):e41. https://doi.org/10.1192/ bjo.2019.34

47. Corsello C, Bal V, Pickles A, et al. Between a ROC and a hard place: Decision making and making decisions about using the SCQ. J Child Psychol Psychiatry. 2007;48:932-940. https://doi.org/10.1111/j.1469-7610.2007.01762.x

48. Oosterling IJ, Swinkels SH, Van der Gaag RJ, Visser JC, Dietz C, Buitelaar JK. Comparative analysis of three screening instruments for autism spectrum disorder in toddlers at high risk. J Autism Dev Disord. 2009;39(6):897-909. https://doi. org/10.1007/s10803-009-0692-9

49. Liu T. Motor milestone development in young children with autism spectrum disorders: An exploratory study. Educ Psychol Pract. 2012;28(3):315-326. https:// doi.org/10.1080/02667363.2012.684340

50. Ozonoff S, Young GS, Goldring S, et al. Gross motor development, movement abnormalities, and early identification of autism. J Autism Dev Disord. 2008;38(4):644-656. https://doi.org/10.1007/s10803-007-0430-0

51. Iverson JM, Fagan MK. Infant vocal-motor coordination: Precursor to the gesturespeech system? Child Dev. 2004;75(4):1053-1066. https://doi.org/10.1111/ j.1467-8624.2004.00725.x

52. Mandich AD, Polatajko HJ, Rodger S. Rites of passage: Understanding participation of children with developmental coordination disorder. Hum Mov Sci. 2003;22(45):583-595. https://doi.org/10.1016/j.humov.2003.09.011

53. Billstedt E, Gillberg IC, Gillberg C. Autism after adolescence: Population-based 13- to 22-year follow-up study of 120 individuals with autism diagnosed in childhood. J Autism Dev Disord. 2005;35(3):351-360. https://doi.org/10.1007/ s10803-005-3302-5

54. Haglund NG, Kallen KB. Risk factors for autism and Asperger syndrome. Perinatal factors and migration. Autism. 2011;15(2):163-183. https://doi.org/10.1177/ 1362361309353614

55. Hultman CM, Sandin S, Levine SZ, Lichtenstein P, Reichenberg A. Advancing paternal age and risk of autism: New evidence from a population-based study and a meta-analysis of epidemiological studies. Mol Psychiatry. 2011;16(12): 1203-1212. https://doi.org/10.1038/mp.2010.121

56. Buchmayer S, Johansson S, Johansson A, Hultman CM, Sparen P, Cnattingius S. Can association between preterm birth and autism be explained by maternal or neonatal morbidity? Pediatrics. 2009:124(5):e817-e825. https://doi.org/10.1542/ peds.2008-3582

57. Tsuchiya KJ, Matsumoto $\mathrm{K}$, Miyachi $\mathrm{T}$, et al. Paternal age at birth and high-functioning autistic-spectrum disorder in offspring. $\mathrm{Br} \mathrm{J}$ Psychiatry. 2008;193(4):316-321. https://doi.org/10.1192/bjp.bp.107.045120 